\title{
A facile approach for grafting bi-functional groups terminated branched polyphosphazene on carbon fibers
}

\author{
Z. J. He, J. H. Liu, S. H. Liu, X. Q. Zhang ${ }^{*}$, C. H. Lei \\ Guangdong Provincial Key Laboratory of Functional Soft Condensed Matter, School of Materials and Energy, \\ Guangdong University of Technology, No.100 Waihuan West Road, 510006 Guangzhou, China
}

Received 22 January 2020; accepted in revised form 22 March 2020

\begin{abstract}
We explored a facile method for grafting bi-functional groups terminated branched polyphosphazene on carbon fibers via direct epoxy amination with an aqueous ammonia solution. The branched polyphosphazene with abundant $\beta$-hydroxyl groups and amino groups significantly changes the chemical composition of carbon fibers surface. A significant improvement in interfacial shear strength was obtained from 43.6 MPa for virgin carbon fibers (C.F.) composites to 89.6 MPa for branched polyphosphazene grafted C.F. composites.
\end{abstract}

Keywords: polymer composites, molecular engineering, carbon fibers, interfaces, polyphosphazene

\section{Introduction}

Carbon fibers (C.F.) reinforced composites can achieve excellent mechanical properties with high specific strength and specific stiffness; hence they have been widely used as structural components [1]. However, the performance of C.F. reinforced composites is, to a large extent, governed by the structure and character of the fiber-matrix interface. Therefore, various strategies such as oxidation, coating, irradiation [2,3] introducing carbon nanotubes or graphene oxide [4-7], chemical grafting [8], have been proposed for improving the interfacial properties of composites [9]. In our previous studies [10 13], an amine-capped cross-linked polyphosphazenes was grafted or coated on carbon fibers through in situ polycondensation between hexachlorocyclotriphosphazene (HCCP) and 4,4'-oxydiphenylamine (ODA) under mild conditions. However, compared with the oxidized C.F./epoxy resin composites, the highest degree of IFSS improvement for the aminecapped cross-linked polyphosphazenes functionalized carbon fiber was only 43.0\% [11]. Additionally, it was found that the cross-linked polyphosphazene layer was brittle owing to the high cross density. This may be the reason for limiting improvement of the interfacial properties. Most recently, it is noteworthy that the chemical grafting of hyperbranched polymers [14-17] or polyamidoamine (PAMAM) dendrimers [18-20] on C.F. has drawn comprehensive attention from researchers. These types of polymers can provide a lot of active polar groups to improve the physical interfacial adhesion or even form strong chemical bonding between fiber and matrix. However, all these chemical modified polymers above contain only mono-functional groups, e.g. amino groups or hydroxyl groups. There are few reports focusing on the modification of carbon fibers with bifunctional groups at the same polymers that can provide more reactive sites to react with epoxy resin. It is expected to gain a better improvement of interfacial properties for the bi-functional groups polymer functionalized carbon fibers.

In the current study, a novel and straightforward approach has been proposed to chemically graft 
bi-functional groups terminated branched polyphosphazene on carbon fibers via direct epoxy amination method [21] using a six-armed epoxy monomer and aqueous ammonia solution $\left(\mathrm{NH}_{3} \cdot \mathrm{H}_{2} \mathrm{O}\right)$. Interestingly, as shown in Figure 1, the grafted branched polyphosphazene has an abundance of hydroxyl groups and amino groups. These two types of active groups simultaneously distributed at the terminus of branched polyphosphazene, which can provide more reactive sites to react with epoxy resin and is expected to increase the chemical bonding density at the interface.

\section{Experimental}

\subsection{Materials}

Commercially available T700S carbon-fibers (denoted as C.F., $12 \mathrm{~K}, 1.80 \mathrm{~g} / \mathrm{cm}^{3}$ ), purchased from Japan Toray Co., Tokyo, Japan. A six-armed epoxy monomer hexa[(4-(2,3-epoxypropyl)-2-methoxy) phenoxy] cyclotriphosphazene (named as EHEP) was synthesized from eugenol and hexachlorocyclotriphosphazene according to our previous work [22]. The chemical structure of EHEP was shown in Figure 1. Ethanediamine (EDA) and thionyl chloride $\left(\mathrm{SOCl}_{2}\right)$ were purchased from Innochem Co., Beijing, China. The E51 $(E E W=200 \mathrm{~g} / \mathrm{eq})$ epoxy resin was obtained from Jinhong Co., Zhejiang, China. The hardener 4,4-diaminodiphenyl methane (DDM, $A H E W=$ $50 \mathrm{~g} / \mathrm{eq}$ ) was obtained from Aladdin Co., Shanghai, China. The chemical structures of E51 and DDM are shown in Figure 4a. Aqueous ammonia solution ( $25 \% \mathrm{NH}_{3}$ basis), acetone, dichloromethane, dioxane and other reagents were obtained from Tianjin Damao Co., Tianjin, China, and used as received.

\subsection{Bi-functional groups terminated branched polyphosphazene grafting of carbon fibers}

The typical procedure of preparation for the bi-functional groups terminated branched polyphosphazene grafting of carbon fibers (denoted as CF-HEA ${ }_{2}$ ) were as follow: (1) The commercial C.F. were refluxed in acetone for $48 \mathrm{~h}$ to remove the sizing, and then oxidized in concentrated $\mathrm{HNO}_{3}$ at $100^{\circ} \mathrm{C}$ for $6 \mathrm{~h}$ to introduce oxygen-containing functional groups onto fiber surfaces (denoted as CF-O). EDA grafted C.F. (named as CF-EA) was prepared according to the report in ref [23]. (2) The CF-EA (1.0 g) was immersed in the EHEP solution $(0.04 \mathrm{mmol} / \mathrm{ml}$ in dioxane), followed by a reflux treatment at $70^{\circ} \mathrm{C}$ for $12 \mathrm{~h}$. EHEP grafted CF-EA (denoted as CF-HDE ${ }_{1}$ ) was obtained after washing with dioxane and drying in

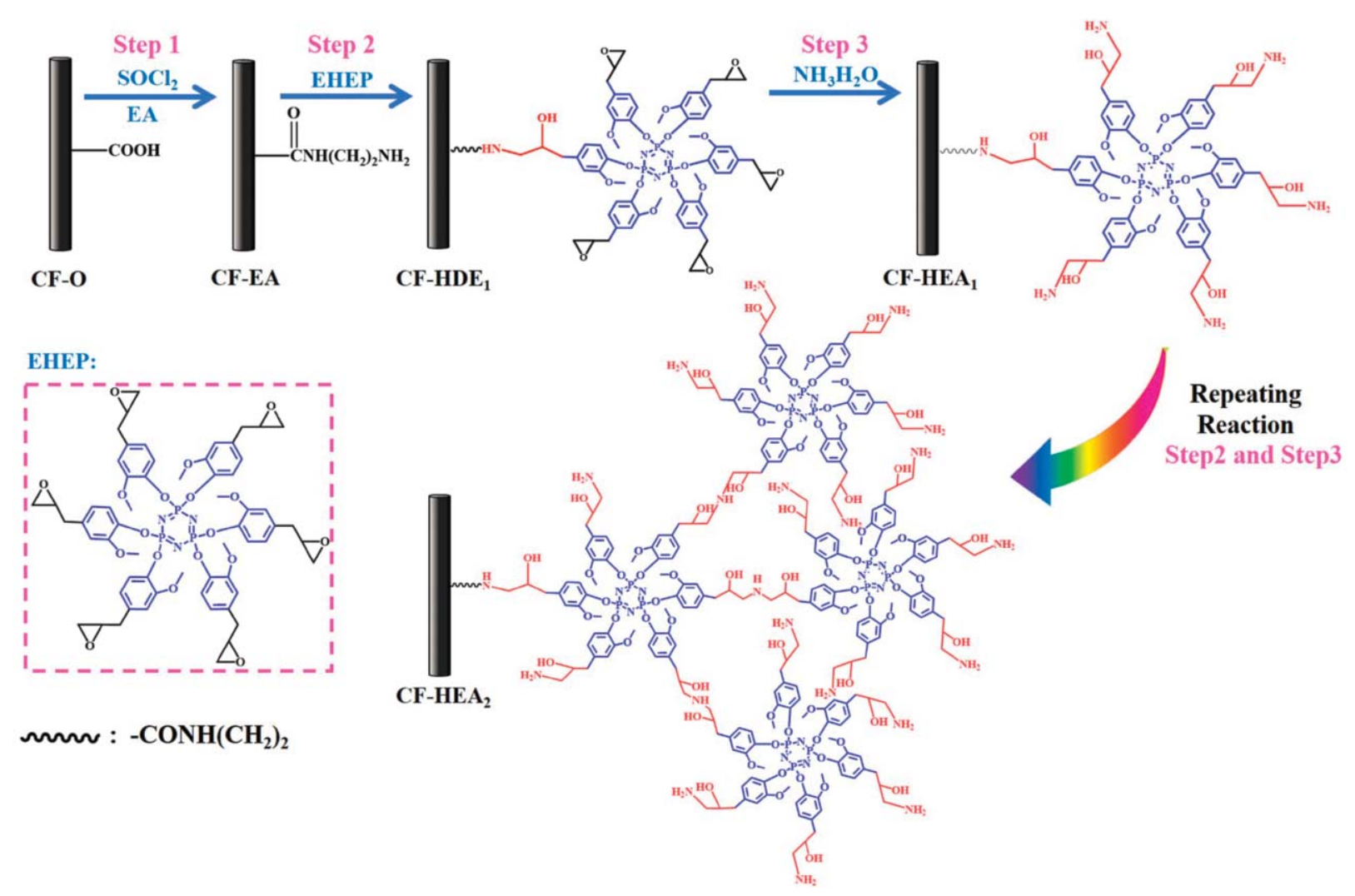

Figure 1. Schematic of branched polyphosphazene grafted on carbon fibers. 
oven at $100^{\circ} \mathrm{C}$. (3) To prepare the bi-functional groups terminated cyclotriphosphazene grafted carbon fibers (named as CF-HEA 1 ), epoxy amination of $\mathrm{CF}-\mathrm{HDE}_{1}$ was carried out according to the ref [21]. CF-HDE 1 (1.0 g) was immersed in $40 \mathrm{ml}$ of dioxane, and $\mathrm{NH}_{3} \cdot \mathrm{H}_{2} \mathrm{O}(25 \%$ solution, $10 \mathrm{ml})$ was then added. The reaction was refluxed at $100^{\circ} \mathrm{C}$ for $5 \mathrm{~h}$. Subsequently, the CF-HEA 1 was taken out and rinsed with deionized water to remove residual $\mathrm{NH}_{3} \cdot \mathrm{H}_{2} \mathrm{O}$, and then dried at $100{ }^{\circ} \mathrm{C}$. After repeating the reaction of step (2) and step (3), the branched bifunctional groups terminated polyphosphazene grafted carbon fibers was obtained, denoted as CF-HEA 2 .

\subsection{Characterization}

The surface topography of carbon fibers was detected by Scanning electron microscope (SEM), which was performed on a Hitachi S-3400 SEM system (Hitachi Co., Japan). X-ray photoelectron spectroscopy (XPS) and Fourier transform infrared spectrometer (FTIR) were used to analyze the chemical composition on the surface of C.F. XPS data was recorded on an Escalab 250Xi XPS system (Thermo Fisher, UK). FTIR was recorded on a Nicolet IS-50 FTIR spectrometer system (Thermo Fisher Scientific, USA).

Interfacial shear strength (IFSS) was tested on an interfacial micro-bond evaluation instrument (Model HM 410, Tohei Sanyon Corporation of Japan). The specimens for the microbond test were prepared by the following procedure: A CF single filament was fixed horizontally onto the metal frame using glue. Some epoxy resin droplets were placed against a single filament and cured (Figure 4a). The formulation of the cured epoxy resin was prepared in a 1.0:1.0 molar ratio of the epoxy group to the active amine hydrogen. The specimens were cured at $90^{\circ} \mathrm{C}$ for $2 \mathrm{~h}$ and $110^{\circ} \mathrm{C}$ for $2 \mathrm{~h}$, and then cooled down to room temperature naturally.

\section{Results and discussion}

The SEM verified the surface topography's changes for the carbon fibers after grafting treatment, and the results are displayed in Figure 2. The oxidized C.F. (CF-O) with a smooth surface was observed. For the CF-EA, there was almost no obvious change on the surface, which was due to the short chain of ethanediamine. After grafting EHEP and amination of epoxy groups with $\mathrm{NH}_{3} \cdot \mathrm{H}_{2} \mathrm{O}$, it is clear that only a sixarmed compound containing cyclotriphosphazene ring was introduced onto fiber surface (Figure 1). Hence, the surface topography of CF-HEA 1 did not change significantly owing to the lack of obvious chemical structure change. However, compared with $\mathrm{CF}_{-\mathrm{HEA}_{1}}$, some small particles distributed on the branched polyphosphazene grafted carbon fiber (CF$\mathrm{HEA}_{2}$ ) surface could be seen as shown in Figure 2d, the size of particles was $80-250 \mathrm{~nm}$, which was determined by SEM photographs. This result suggested that the surface roughness of the carbon fiber increased with repeated grafting of EHEP and amination reactions, which was beneficial to enhancing the mechanical interlocking between C.F. and matrix.

The surface chemical composition of CF-O and modified C.F.s were characterized by XPS, as shown in Figure 3, the detailed results are listed in Table 1. As can be seen in Figure 3a, two characteristic peaks assigned to $\mathrm{C} 1 \mathrm{~s}(\sim 284.8 \mathrm{eV})$ and $\mathrm{O} 1 \mathrm{~s}(\sim 532.1 \mathrm{eV})$, and a small amount of N1s $(\sim 399.5 \mathrm{eV})$ were observed in CF-O. In the case of the CF-HEA 2 , a new signal of $\mathrm{P} 2 \mathrm{p}$ peak at $133.5 \mathrm{eV}$ was found beside the signals of $\mathrm{C} 1 \mathrm{~s}, \mathrm{~N} 1 \mathrm{~s}$ and $\mathrm{O} 1 \mathrm{~s}$, and the atom percentage of N1s in CF-HEA 2 dramatically increased from 2.7 to $5.1 \%$ (Table 1). These results suggested that the carbon fibers were successfully grafted with polyphosphazene, which contained phosphorus and nitrogen. In addition, $\mathrm{CF}-\mathrm{HEA}_{2}$ has higher $\mathrm{N} / \mathrm{C}$ ratio (6.6) and $\mathrm{O} / \mathrm{C}$ ratio (21.8) than $\mathrm{CF}-\mathrm{O}(\mathrm{N} / \mathrm{C}=3.3$, $\mathrm{O} / \mathrm{C}=20.0$ ), suggesting that a large number of polar groups could be incorporated on carbon fibers, which might improve the fiber surface wettability. To further verify the types of functional groups on carbon fibers, we used high-resolution XPS to analyze the surface composition and chemical environment of $\mathrm{CF}-\mathrm{O}$ and $\mathrm{CF}-\mathrm{HEA}_{2}$. Figure $3 \mathrm{~b}$ shows the N1s XPS spectrum of CF-O, a component peak at $399.2 \mathrm{eV}$ was assigned to $\mathrm{C}-\mathrm{N}=\mathrm{C}$ that was derived from the carbonization procedure of polyacrylonitrile (PAN) based carbon fibers [24]. For the CF$\mathrm{HEA}_{2}$, there was deconvoluted three peaks at 397.2, 399.1 and $401.3 \mathrm{eV}$ in the N1s XPS spectrum (Figure 3c) [25-27], which were attributed to the phosphazenic nitrogen $(-\mathrm{P}=\mathrm{N}-)$ of the cyclotriphosphazene, new generated terminal primary amine $\left(-\mathrm{NH}_{2}\right)$ /secondary amine (-NH-) and hydrogen bonded amines [26-27], respectively, indicating a lot of amino groups were introduced on carbon fibers. Additionally, compared with CF-O (Figure 3d), O1s XPS spectrum of CF-HEA 2 revealed new component peaks at 531.6, 532.5 and $533.5 \mathrm{eV}[28,29]$, 

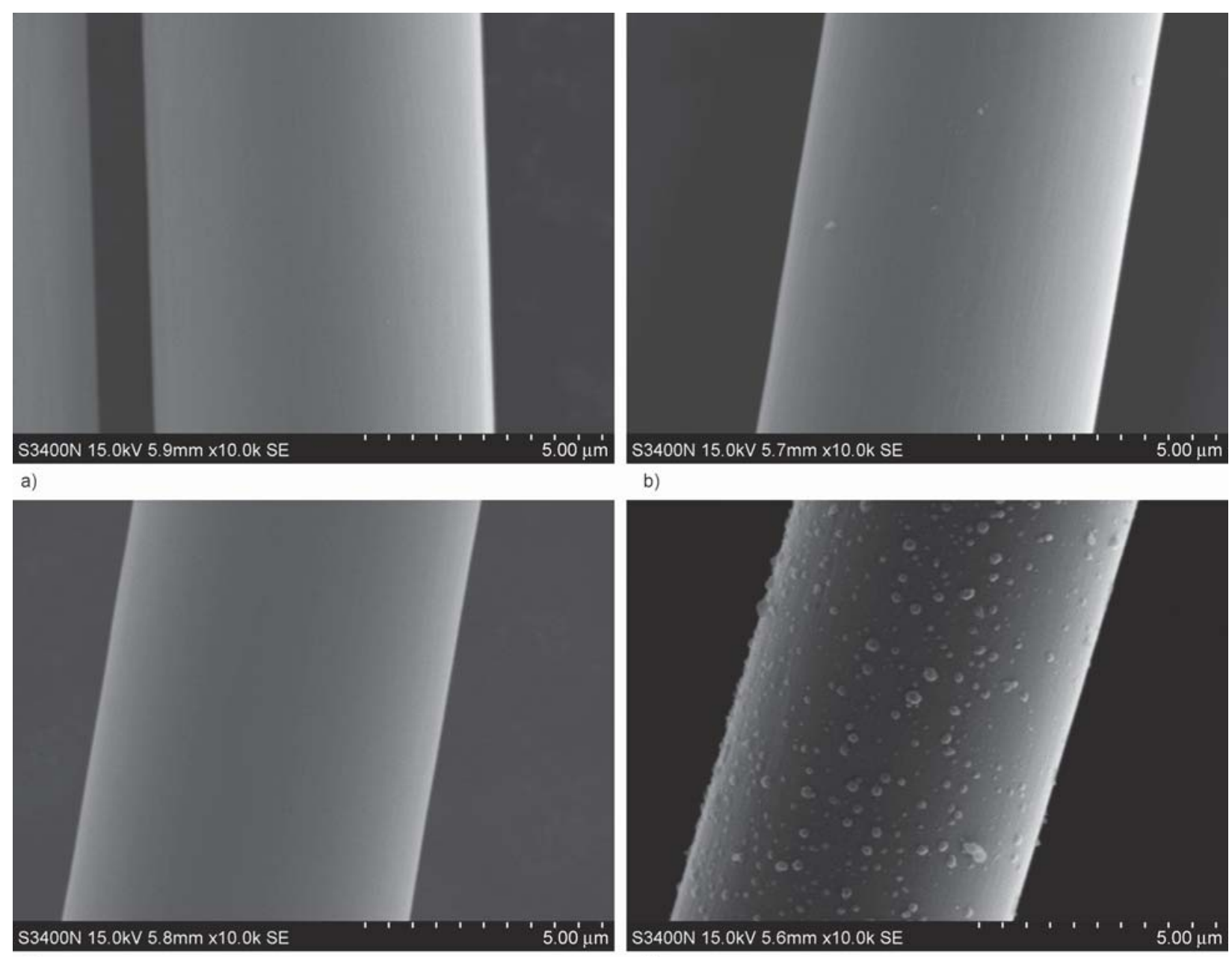

b)

c)

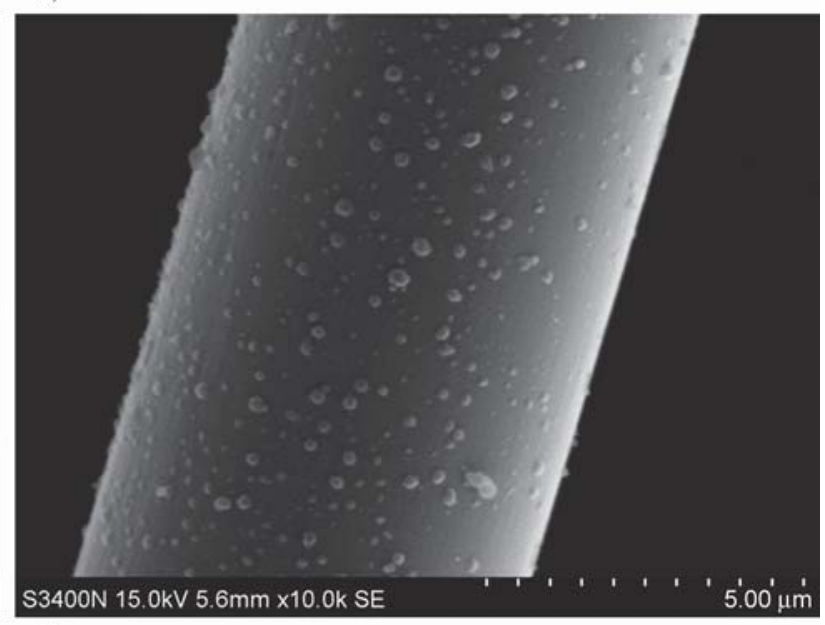

d)

Figure 2. The SEM images of CF-O (a), CF-EA (b), CF-HEA 1 (c) and CF-HEA 2 (d).

which were assigned to $(\mathrm{Ph})-\mathrm{O}-\mathrm{CH}_{3}$, secondary alcohol $(\mathrm{CH}-\mathrm{OH})$ and $(\mathrm{Ph})-\mathrm{O}-\mathrm{P}$, respectively. This observation suggested that a large abundant of $\beta$ hydroxyl groups were also incorporated on fiber surface.

Figure $3 \mathrm{f}$ shows the FTIR spectrum of CF-HEA 2 compared with that of CF-O. There was a typical peak at $\sim 3436 \mathrm{~cm}^{-1}$, which was attributed to $\mathrm{O}-\mathrm{H}$ stretching vibration due to carboxyl groups and hydroxyl groups on CF-O surface. After grafting branched polyphosphazene on C.F., several new peaks appeared in the FTIR spectrum of CF-HEA 2 . The characteristic peak at $3431 \mathrm{~cm}^{-1}(1), 3171 \mathrm{~cm}^{-1}$ (2) shoulder peak, $1627 \mathrm{~cm}^{-1}(3), 1404 \mathrm{~cm}^{-1}$ (4), $1120 \mathrm{~cm}^{-1}(5)$, were assigned to $\mathrm{O}-\mathrm{H}$ stretching vibration of a secondary alcohol $(\mathrm{CHO}-\mathrm{H})$, to $\mathrm{N}-\mathrm{H}$ stretching vibration of primary amine $\left(\mathrm{CH}_{2}-\mathrm{NH}_{2}\right)$ and secondary amine $(\mathrm{CH}-\mathrm{NH}-\mathrm{CH})$, to the $\mathrm{C}=\mathrm{C}$ stretching vibration of the benzene ring, to the $\mathrm{O}-\mathrm{H}$ formation vibration of a secondary alcohol $(\mathrm{CHO}-\mathrm{H})$, to the $-\mathrm{P}=\mathrm{N}-$ asymmetric stretching vibration of cyclotriphosphazene ring. These features clearly verified that the surface of CF-HEA 2 contained both hydroxyl groups and amino groups, corresponding to the XPS results. Hence, based on the XPS and FTIR results, it is confirmed that a large number of hydroxyl groups and amino groups were successfully introduced on carbon fibers through grafting branched polyphosphazene via epoxy amination method and repeating reactions as displayed in Figure 1, which is expected to improve the surface wettability and provide abundant active sites to form strong chemical bonding at the interface of composites.

As displayed in Figure 4, the IFSS results of CF-O/ EP, CF-EA/EP, CF-HEA1/EP and CF-HEA $2 /$ EP are $43.6,65.3,76.8$ and $89.6 \mathrm{MPa}$, respectively. It is found that bi-functional groups grafted carbon fibers exhibited higher interfacial shear strength than that of CF-O and CF-EA. CF-HEA 2 /EP composites yield an IFSS of $89.6 \mathrm{MPa}$, which has an increase of about $105 \%$ in comparison with CF-O/EP composites $(43.6 \mathrm{MPa})$ and about $37 \%$ in comparison with 

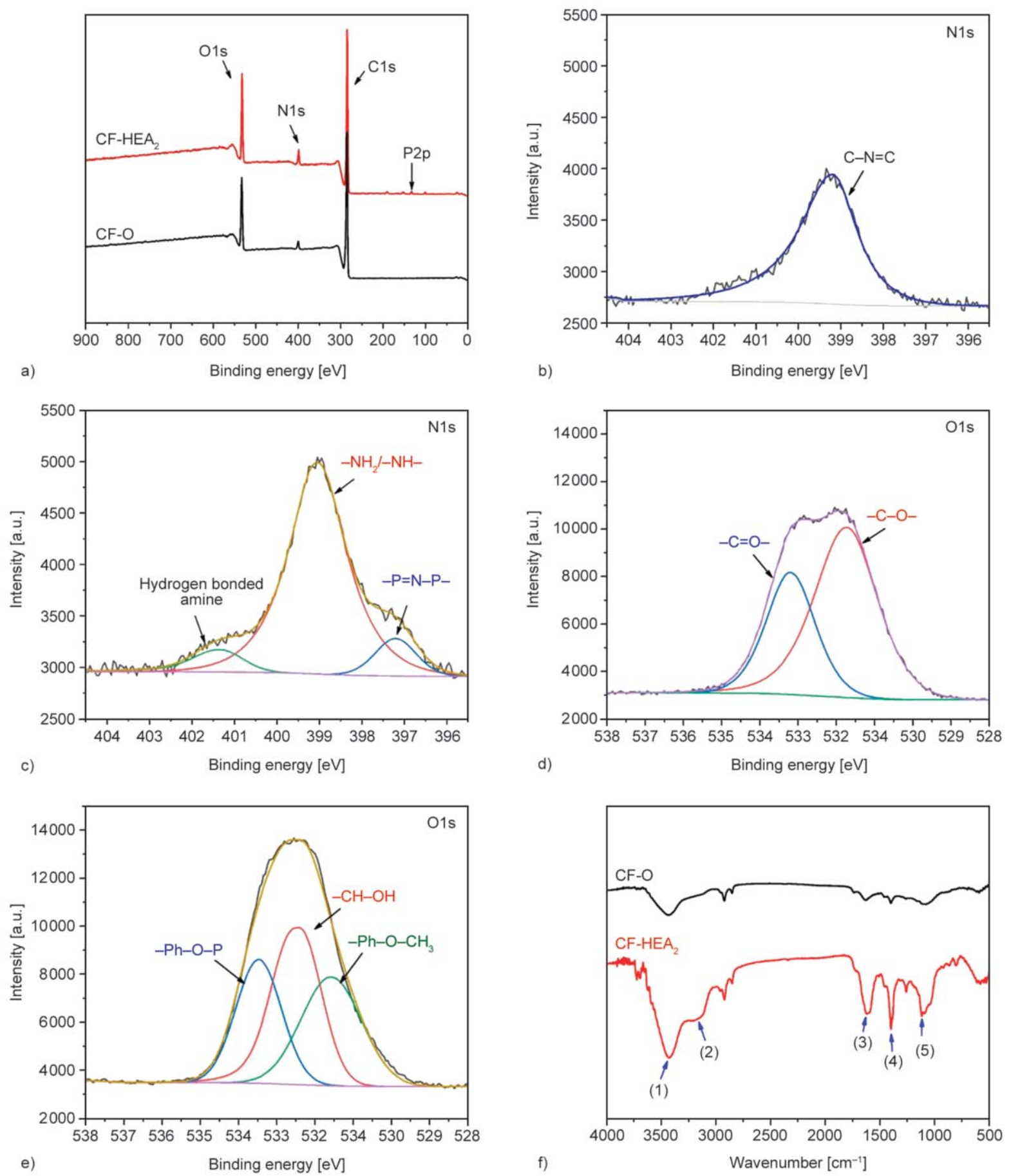

Figure 3. The wide XPS spectra of CF-O and CF-HEA 2 (a); N1s XPS spectra of CF-O (b) and CF-HEA 2 (c); O1s XPS spectra of CF-O (d) and CF-HEA 2 (e); FTIR spectra of CF-O and CF-HEA 2 (f).

CF-EA/EP composites (65.3 MPa). It is noteworthy that the IFSS of CF-HEA2/EP is higher than that of

Table 1. Surface element composition of $\mathrm{CF}-\mathrm{O}$ and CF-HEA 2 .

\begin{tabular}{|l|c|c|c|c|c|c|}
\hline \multirow{2}{*}{ Samples } & \multicolumn{4}{|c|}{$\begin{array}{c}\text { Element content } \\
\text { [atom\%] }\end{array}$} & \multicolumn{2}{c|}{$\begin{array}{c}\text { Atomic ratio } \\
\text { [\%] }\end{array}$} \\
\hline & C1s & O1s & N1s & P1s & O/C & N/C \\
\hline CF-O & 81.3 & 16.0 & 2.7 & - & 20.0 & 3.3 \\
\hline CF-HEA 2 & 77.1 & 16.8 & 5.1 & 1.0 & 21.8 & 6.6 \\
\hline
\end{tabular}

CF-HEA $1 / E P$ as a result of more bi-functional groups generated on fiber surface through repeating reaction. Additionally, the degree of interfacial shear strength improvement for the bi-functional groups terminated polyphosphazene grafted carbon fiber composites $\left(\mathrm{CF}-\mathrm{HEA}_{2} / \mathrm{EP}\right)$ is also better than those of other polyphosphazenes modified carbon fibers composites reported in our previous studies [11-13]. Furthermore, the advantages of this method for 
interfacial improvement can be further verified in contrast with the other parameter appeared in the literature $[14,17,20]$. For example, Shi et al. [14] reported a $54.6 \%$ enhancement of IFSS for the hydroxyl-terminated hyperbranched polymer grafted on carbon fiber in comparison with the untreated carbon fibers.

To help to understand the interface behavior and improving mechanism of CF-HEA $/$ EP composites, we examined the surface topography of single carbonfiber after debonding from the epoxy matrix, as shown in Figure $4 \mathrm{c}$ and $4 \mathrm{~d}$. It can be clearly seen that there was almost no epoxy resin remained on the debonded CF-O surface, indicating that the matrix completely detached from the fiber surface due to the weak adhesion [12]. By contrast, a substantial amount of the epoxy resin still adhered to the CF$\mathrm{HEA}_{2}$ surface (Figure $4 \mathrm{c}$ ). The development of this fracture microstructure should be related to the interaction between carbon fiber and matrix. XPS and FTIR results clearly confirmed that a large amount of hydroxyl groups and amino groups distributed on carbon fibers, which can react with epoxy in matrix resin. Moreover, Mora et al. [21] found that the $\beta$-hydroxyl groups of amine afforded good reactivity properties and accelerated the rate of amine curing. These indicated that strong chemical bonding would be formed between fiber and matrix. In addition, the particles on the carbon fiber surface might also enhance the mechanical interlocking on the interface to some extent $[4,5]$. Thereby, the strong chemical linking, as well as mechanical interlocking between $\mathrm{CF}_{-} \mathrm{HEA}_{2}$ and epoxy, mainly contribute to the obvious improvement of the interfacial strength.

\section{Conclusions}

In this study, a novel bi-fucntional groups terminated polyphosphazene grafted on carbon fiber was fabricated via the epoxy amination method. A large number of hydroxylamine could facilitate to form strong chemical bonding, the particles of grafted polyphosphazene could also enhance mechanical interlocking between carbon fibers and epoxy resin. The IFSS of CF-HEA 2 /EP composites could obtain about $105 \%$ improvement compared with that of CF-O/EP composites. This processing of $\mathrm{HEA}_{2}$ grafted carbon a)

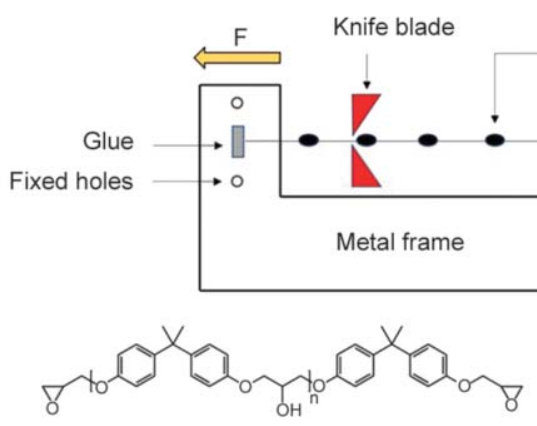

E51

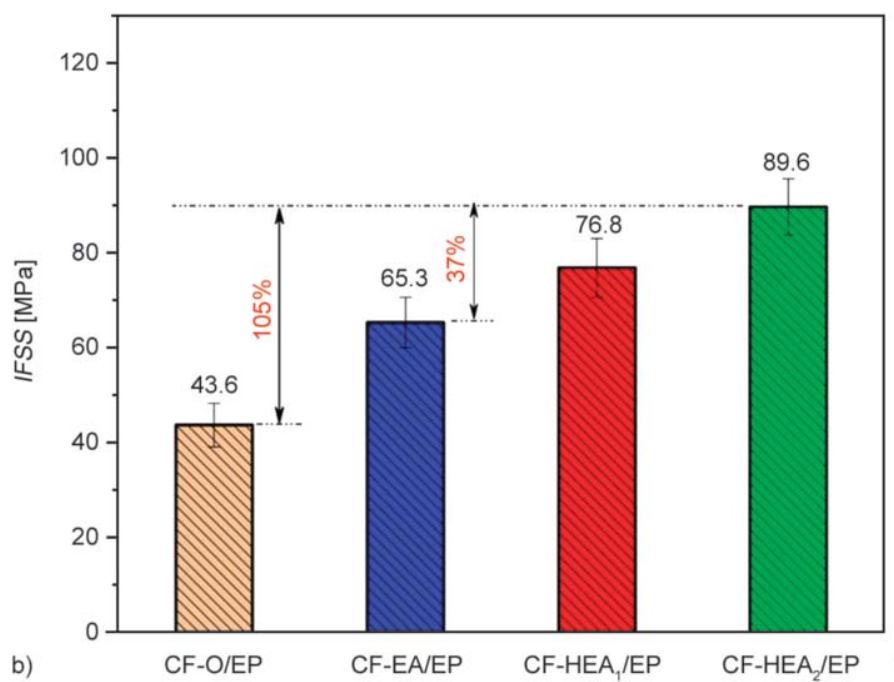

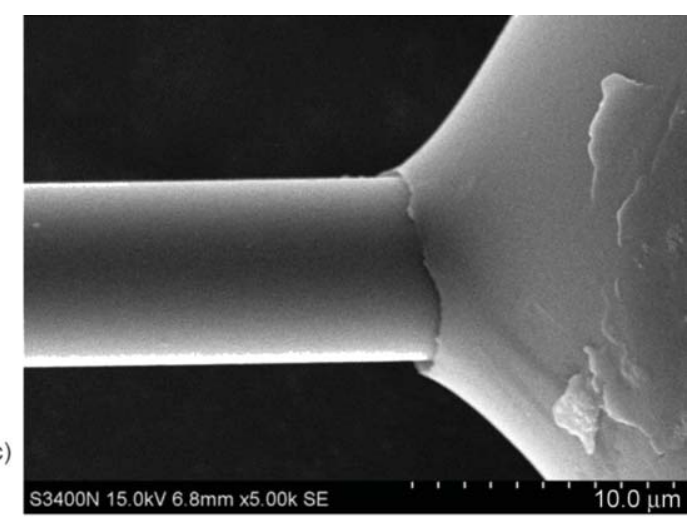

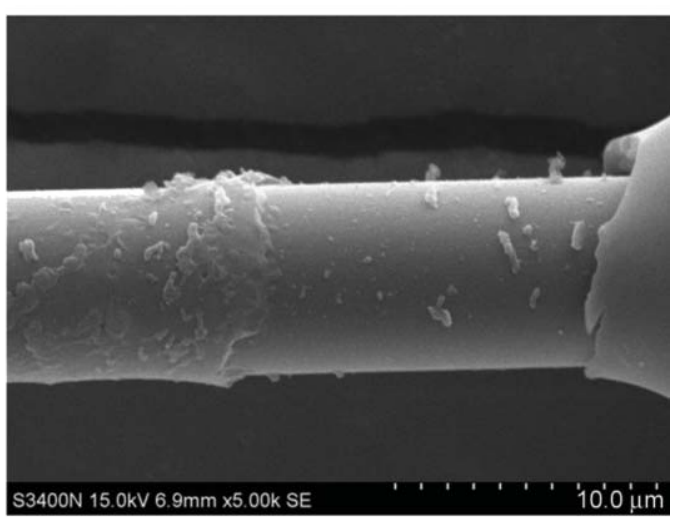

Figure 4. The schematic of IFSS test sample (a). The IFSS results of single CF/EP composites (b); SEM images after debonding: CF-O/EP (c); CF-HEA 2 /EP (d) 
fibers through epoxy amination method would provide a novel and effective approach to functionalize the carbon fibers and improve the interfacial performance of the composites.

\section{Acknowledgements}

This study were financially supported by the Guangzhou Science and Technology Plan Project (No.20180410326), Guangdong Province Research and Development Plan of Key Areas (No.2019B010929001) and the Guangzhou Emerging Industry Development Fund Project of the Guangzhou Development and Reform Commission.

\section{References}

[1] Paiva M. C., Bernardo C. A., Nardin M.: Mechanical, surface and interfacial characterisation of pitch and PANbased carbon fibres. Carbon, 38, 1323-1337 (2000). https://doi.org/10.1016/S0008-6223(99)00266-3

[2] Shan M., Wang H., Xu Z., Li N., Chen C., Shi J., Liu L., Kuang L., Ma M., Zhang C.: Synergetic improvement of mechanical properties and surface activities in $\gamma$-irradiated carbon fibers revealed by radial positioning spectroscopy and mechanical model. Analytical Methods, 10, 496-503 (2018). https://doi.org/10.1039/c7ay02852k

[3] Xu Z., Huang Y., Zhang C., Liu L., Zhang Y., Wang L.: Effect of $\gamma$-ray irradiation grafting on the carbon fibers and interfacial adhesion of epoxy composites. Composites Science and Technology, 67, 3261-3270 (2007). https://doi.org/10.1016/j.compscitech.2007.03.038

[4] Chen L., Jin H., Xu Z., Shan M., Tian X., Yang C., Wang Z., Cheng B.: A design of gradient interphase reinforced by silanized graphene oxide and its effect on carbon fiber/epoxy interface. Materials Chemistry and Physics, 145, 186-196 (2014).

https://doi.org/10.1016/j.matchemphys.2014.02.001

[5] Sui X., Shi J., Yao H., Xu Z., Chen L., Li X., Ma M., Kuang L., Fu H., Deng H.: Interfacial and fatigue-resistant synergetic enhancement of carbon fiber/epoxy hierarchical composites via an electrophoresis deposited carbon nanotube-toughened transition layer. Composites Part A: Applied Science and Manufacturing, 92, 134-144 (2017).

https://doi.org/10.1016/j.compositesa.2016.11.004

[6] Zhao Z., Teng K., Li N., Li X., Xu Z., Chen L., Niu J., Fu H., Zhao L., Liu Y.: Mechanical, thermal and interfacial performances of carbon fiber reinforced composites flavored by carbon nanotube in matrix/interface. Composite Structures, 159, 761-772 (2017). https://doi.org/10.1016/j.compstruct.2016.10.022
[7] Zhang C., Liu L., Xu Z., Lv H., Wu N., Zhou B., Mai W., Zhao L., Tian X., Guo X.: Improvement for interface adhesion of epoxy/carbon fibers endowed with carbon nanotubes via microwave plasma-enhanced chemical vapor deposition. Polymer Composites, 39, E1262E1268 (2018). https://doi.org/10.1002/pc.24843

[8] Xu Z., Wu X., Sun Y., Jiao Y., Li J., Chen L., Lu L.: Surface modification of carbon fiber by redox-induced graft polymerization of acrylic acid. Journal of Applied Polymer Science, 108, 1887-1892 (2008).

https://doi.org/10.1002/app.27874

[9] Raphael N., Namratha K., Chandrashekar B. N., Sadasivuni K. K., Ponnamma D., Smitha A. S., Krishnaveni S., Cheng C., Byrappa K.: Surface modification and grafting of carbon fibers: A route to better interface. Progress in Crystal Growth and Characterization of Materials, 64, 75-101 (2018).

https://doi.org/10.1016/j.pcrysgrow.2018.07.001

[10] Zhang X., Xu H., Fan X.: Grafting of amine-capped cross-linked polyphosphazenes onto carbon fiber surfaces: A novel coupling agent for fiber reinforced composites. RSC Advances, 4, 12198-12205 (2014). https://doi.org/10.1039/c3ra47213b

[11] Cheng X., He Z., Luo Y., Zhang X., Lei C.: Manipulating interfacial strength of polyphosphazene functionalized carbon fiber composites. Polymer Composites, 40, E1831-E1839 (2019). https://doi.org/10.1002/pc.25171

[12] Xu H., Zhang X., Liu D., Yan C., Chen X., Hui D., Zhu Y.: Cyclomatrix-type polyphosphazene coating: Improving interfacial property of carbon fiber/epoxy composites and preserving fiber tensile strength. Composites Part B: Engineering, 93, 244-251 (2016). https://doi.org/10.1016/j.compositesb.2016.03.033

[13] Chen X., Xu H., Liu D., Yan C., Zhu Y.: A facile onepot fabrication of polyphosphazene microsphere/carbon fiber hybrid reinforcement and its effect on the interfacial adhesion of epoxy composites. Applied Surface Science, 410, 530-539 (2017). https://doi.org/10.1016/j.apsusc.2017.03.104

[14] Shi L., Ma L., Li P., Wang M., Guo S., Han P., Song G.: The effect of self-synthesized hydroxyl-terminated hyperbranched polymer interface layer on the properties of carbon fiber reinforced epoxy composites. Applied Surface Science, 479, 334-343 (2019). https://doi.org/10.1016/j.apsusc.2019.02.090

[15] Li S., Zhu H., Lv T., Lin Q., Hou H., Li Y., Wu Q., Cui C.: The effect of amino-terminated hyperbranched polymers on the impact resistance of epoxy resins. Colloid and Polymer Science, 294, 607-615 (2016). https://doi.org/10.1007/s00396-015-3811-5 
[16] Ma L., Meng L., Wu G., Wang Y., Zhao M., Zhang C., Huang Y.: Improving the interfacial properties of carbon fiber-reinforced epoxy composites by grafting of branched polyethyleneimine on carbon fiber surface in supercritical methanol. Composites Science and Technology, 114, 64-71 (2015).

https://doi.org/10.1016/j.compscitech.2015.04.011

[17] Ma L., Meng L., Wu G., Wang Y., Zhao M., Zhang C., Huang Y.: Effects of bonding types of carbon fibers with branched polyethyleneimine on the interfacial microstructure and mechanical properties of carbon fiber/epoxy resin composites. Composites Science and Technology, 117, 289-297 (2015).

https://doi.org/10.1016/j.compscitech.2015.06.018

[18] Zhang R. L., Gao B., Zhang J., Cui H. Z., Li D. W.: Propagation of PAMAM dendrimers on the carbon fiber surface by in situ polymerization: A novel methodology for fiber/matrix composites. Applied Surface Science, 359, 812-818 (2015).

https://doi.org/10.1016/j.apsusc.2015.10.204

[19] Peng Q., Li Y., He X., Lv H., Hu P., Shang Y., Wang C., Wang R., Sritharan T., Du S.: Interfacial enhancement of carbon fiber composites by poly(amido amine) functionalization. Composites Science and Technology, 74, 37-42 (2013).

https://doi.org/10.1016/j.compscitech.2012.10.005

[20] Ma L., Meng L., Fan D., He J., Yu J., Qi M., Chen Z., Huang Y.: Interfacial enhancement of carbon fiber composites by generation 1-3 dendritic hexamethylenetetramine functionalization. Applied Surface Science, 296, 61-68 (2014).

https://doi.org/10.1016/j.apsusc.2014.01.039

[21] Mora A. S., Tayouo R., Boutevin B., David G., Caillol S.: Vanillin-derived amines for bio-based thermosets. Green Chemistry, 20, 4075-4084 (2018).

https://doi.org/10.1039/c8gc02006j

[22] Liu J., He Z., Wu G., Zhang X., Zhao C., Lei C.: Synthesis of a novel nonflammable eugenol-based phosphazene epoxy resin with unique burned intumescent char. Chemical Engineering Journal, 390, 124620/1124620/11 (2020).

https://doi.org/10.1016/J.CEJ.2020.124620
[23] He X., Zhang F., Wang R., Liu W.: Preparation of a carbon nanotube/carbon fiber multi-scale reinforcement by grafting multi-walled carbon nanotubes onto the fibers. Carbon, 45, 2559-2563 (2007).

https://doi.org/10.1016/j.carbon.2007.08.018

[24] Tran M. Q., Ho K. K. C., Kalinka G., Shaffer M. S. P., Bismarck A.: Carbon fibre reinforced poly(vinylidene fluoride): Impact of matrix modification on fibre/polymer adhesion. Composites Science and Technology, 68, 1766-1776 (2008). https://doi.org/10.1016/j.compscitech.2008.02.021

[25] Vassileva P., Krastev V., Lakov L., Peshev O.: XPS determination of the binding energies of phosphorus and nitrogen in phosphazenes. Journal of Materials Science, 39, 3201-3202 (2004). https://doi.org/10.1023/B:JMSC.0000025859.82714.4a

[26] Song X., Ma Y., Wang C., Dietrich P. M., Unger W. E. S., Luo Y.: Effects of protonation, hydrogen bonding, and photodamaging on C-ray spectroscopy of the amine terminal group in aminothiolate monolayers. Journal of Physical Chemistry C, 116, 12649-12654 (2012). https://doi.org/10.1021/jp302716w

[27] Graf N., Yegen E., Gross T., Lippitz A., Weigel W., Krakert S., Terfort A., Unger W. E. S.: XPS and NEXAFS studies of aliphatic and aromatic amine species on functionalized surfaces. Surface Science, 603, 28492860 (2009). https://doi.org/10.1016/j.susc.2009.07.029

[28] Lau K. K. S., Gleason K. K.: Particle surface design using an all-dry encapsulation method. Advanced Materials, 18, 1972-1977 (2006). https://doi.org/10.1002/adma.200600896

[29] Amaral I. F., Granja P. L., Barbosa M. A.: Chemical modification of chitosan by phosphorylation: An XPS, FT-IR and SEM study. Journal of Biomaterials Science, Polymer Edition, 16, 1575-1593 (2005). https://doi.org/10.1163/156856205774576736 